\title{
Serum osteocalcin in rheumatoid arthritis and other inflammatory arthritides: relation between inflammatory activity and the effect of glucocorticoids and remission inducing drugs
}

\author{
EVA AF EKENSTAM, SVERKER LJUNGHALL, AND \\ ROGER HÄLLGREN \\ From the Department of Internal Medicine, University Hospital, Uppsala, Sweden
}

SUMMARY Osteocalcin, a vitamin $\mathrm{K}$ dependent protein synthesised by osteoblasts, was measured in serum by radioimmunoassay in patients with rheumatoid arthritis $(n=36)$ and seronegative spondyloarthropathies $(n=23)$. The serum osteocalcin levels were decreased in both patient groups compared with the levels measured in age and sex matched healthy controls. We found no relation between serum osteocalcin and the disease duration or inflammatory activity of the patients who were without drug treatment at the first examination. After administration of glucocorticoids (20 mg prednisolone a day) circulating osteocalcin decreased significantly after one week of treatment. During gradual reduction of the steroid dosage osteocalcin returned to pretreatment values. Treatment with non-steroidal anti-inflammatory drugs (NSAIDs) did not influence circulating osteocalcin. During treatment with chloroquine or penicillamine serum osteocalcin increased significantly, concomitant with a reduction of the acute phase reactants. Controversy persists about the abnormality of bone turnover in rheumatic diseases, but our data suggest that the overall bone turnover is decreased in patients with rheumatoid arthritis and other inflammatory arthritides.

Key words: alkaline phosphatase, ESR, haptoglobin, chloroquine, penicillamine, NSAID.

Previous studies have suggested that patients with rheumatoid arthritis (RA) may suffer not only from periarticular but also generalised alteration in bone metabolism. ${ }^{12}$ The propensity for the development of osteoporosis in rheumatoid arthritis is still a poorly understood phenomenon but is probably due to a number of factors; the inflammatory disease itself, prolonged immobility, and corticosteroid treatment can all be expected to favour the development of osteopenia. Radiological methods have generally been employed to determine the degree of bone loss occurring in RA. Since these methods lack satisfactory sensitivity there has been a search for other techniques; whole body retention of ${ }^{99 \mathrm{~m}} \mathrm{Tc}$ diphosphonate ${ }^{34}$ or ${ }^{99 \mathrm{~m}} \mathrm{Tc}$ pyrophosphate uptake

Accepted for publication 31 October 1985.

Correspondence to Dr Roger Hällgren, Section of Rheumatology, Department of Internal Medicine, University Hospital, S-751 85 Uppsala, Sweden. over the lumbar spine ${ }^{5}$ are examples of more sophisticated methods used during recent years. 을

In this study we have measured the circulating $>$ levels of osteocalcin in inflammatory rheumatic diseases in an attempt to elucidate the metabolic N activity of bone in these disorders and the possible effect of antirheumatic drugs on bone turnover. The $N$ vitamin $\mathrm{K}$ dependent protein osteocalcin is the most $\mathrm{\omega}$ abundant non-collagenous protein in bone ${ }^{67}$ and is probably synthesised only by osteoblasts. ${ }^{89}$ Theo presence of osteocalcin in the circulation may therefore provide a specific chemical index of $\stackrel{(?)}{?}$ osteoblastic activity. In fact the level of serum 0 osteocalcin is increased in disorders characterised by

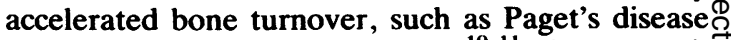
of bone and hyperparathyroidism. ${ }^{10}$ 11 The osteocal- $-{ }_{\mathbb{Q}}$ cin values in our patients with rheumatoid arthritis and other inflammatory arthritides were compared with those in controls matched for age and sex, 
factors influencing circulating osteocalcin. ${ }^{12}$ The osteocalcin data were correlated with the disease duration and activity. The acute effects on serum osteocalcin due to corticosteroid or NSAID treatment were studied. Finally, serum osteocalcin was measured serially in a number of patients treated with remission inducing drugs or low dosage of prednisolone.

\section{Patients and methods}

Venous blood was collected into venoject tubes (Terumo, Tokyo, Japan) from 36 patients with definite or classical rheumatoid arthritis according to American Rheumatism Association criteria and from 23 patients with seronegative spondyloarthropathies (psoriasis arthropathy $(n=6)$, ankylosing pelvospondylitis $(n=7)$, Reiter's disease $(n=1)$, mixed connective tissue disease $(n=3)$, postinfectious arthritis $(n=1)$, and non-classified arthritis $(n=5))$. Clinical and laboratory data are presented in Table 1. At the beginning of the study the patients were not on drug therapy, but some of them had received previous treatment with remission inducing antirheumatic drugs. This therapy had been withdrawn at least three months before the study because of lack of response or side effects. Most of the patients had been on NSAIDs during the last month which were stopped three to four days before the first blood sampling. After collection of blood samples different drug treatments were instituted. All patients were inpatients both initially and at the follow up examinations.

Controls were 58 age and sex matched individuals from the same geographic area participating in a general health survey. They were all apparently healthy and none of them was taking any medications.

All samples were drawn in the morning and in the fasting state. Sera were separated by centrifugation 40-60 minutes after venepuncture and stored frozen at $-70^{\circ} \mathrm{C}$ for six months to two years until analysed on the same occasion. The patient and control samples had been frozen and thawed three times before osteocalcin analysis.
The serum concentrations of osteocalcin were measured by a radioimmunoassay method (Immunonuclear, Stillwater, Minnesota) according to the manufacturer's instructions. The intra-assay and day to day variation of the osteocalcin measurements was $<12 \%$, and the minimum detectable

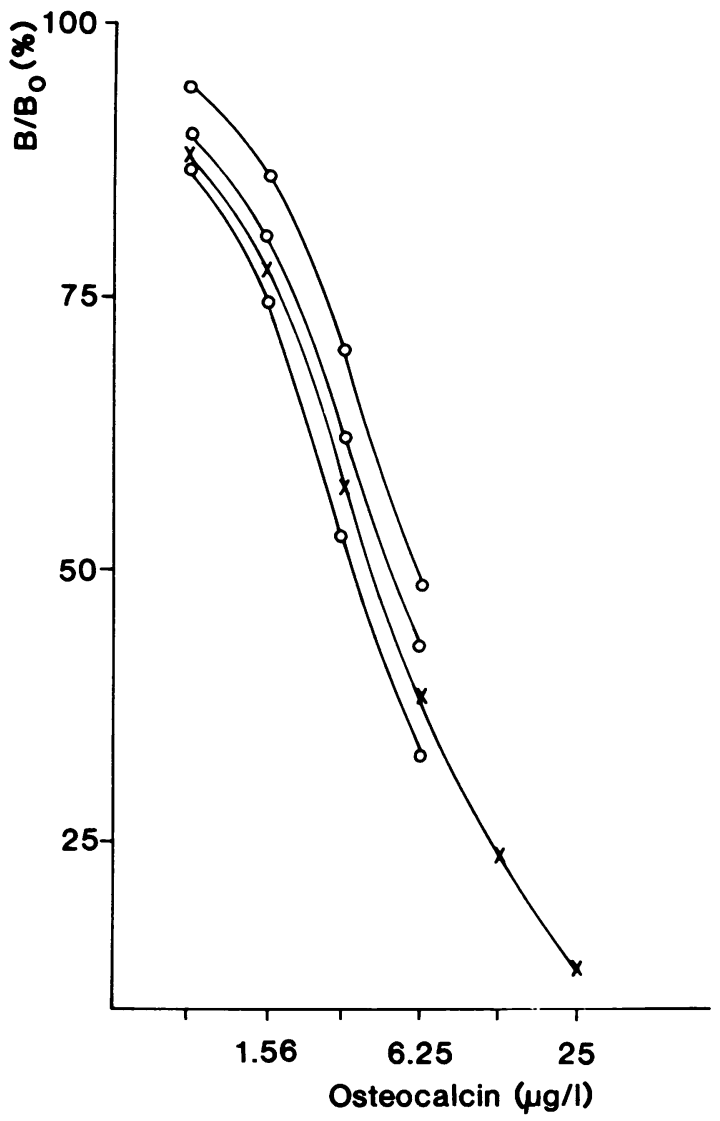

Fig. 1 Dilution curves from sera of three patients with rheumatoid arthritis $(\mathrm{O}-\mathrm{O})$ compared with the standard curve $(X-X) . B / B_{o}=$ (cpm of standard or sample - cpm of non-specific binding)/(cpm of standard buffer-cpm of non-specific binding).

Table 1 Laboratory and clincical data on patients with inflammatory arthritides

\begin{tabular}{|c|c|c|c|c|c|c|c|}
\hline Diagnosis & Sex & $\begin{array}{l}\text { Age* } \\
\text { (years) }\end{array}$ & $n$ & $\begin{array}{l}\text { Osteocalcint } \\
(\mu g / l)\end{array}$ & $\begin{array}{l}E S R+ \\
(\mathrm{mm} / 1 \mathrm{st} h)\end{array}$ & $\begin{array}{l}\text { Haptoglobint } \\
(\mathrm{g} / \mathrm{l})\end{array}$ & $\begin{array}{l}\text { Alkaline } \\
\text { phosphataset } \\
(\mu k a t / l)\end{array}$ \\
\hline \multirow[t]{2}{*}{ Rheumatoid arthritis } & Q & $51(20-69)$ & 26 & $1 \cdot 7(0 \cdot 7-4 \cdot 0)$ & $52 \pm 27$ & $3 \cdot 3 \pm 1 \cdot 2$ & $3 \cdot 0 \pm 1 \cdot 0$ \\
\hline & $\stackrel{+}{\sigma}$ & $50(25-67)$ & 10 & $2.7(1.6-4.4)$ & $43 \pm 14$ & $4 \cdot 4 \pm 1 \cdot 5$ & $3.5 \pm 0.6$ \\
\hline \multirow{2}{*}{ Seronegative spondyloarthropathies } & 우 & $49(26-67)$ & 11 & $1 \cdot 1(0 \cdot 4-3 \cdot 1)$ & $68 \pm 28$ & $3 \cdot 6 \pm 1 \cdot 6$ & $2 \cdot 7 \pm 0.8$ \\
\hline & $\stackrel{+}{\sigma}$ & $46(28-60)$ & 12 & $2.2(1.5-3.4)$ & $56 \pm 33$ & $4 \cdot 2 \pm 1 \cdot 1$ & $4 \cdot 1 \pm 1 \cdot 9$ \\
\hline
\end{tabular}

${ }^{*}$ Means with actual ranges; tmean $\pm \mathrm{SD}$ or $\mathrm{SD}$ range. 
amount was $0 \cdot 3 \mu \mathrm{g} / \mathrm{l}$. In order to study the possible interaction of osteocalcin substances in the osteocalcin assay serum dilution curves were constructed and compared with a standard curve. Parallel serum and standard curves were achieved, indicating an adequate specificity of the determinations (Fig. 1). The logarithmic values of serum osteocalcin were used when comparing groups and for correlative analyses since highly skewed distributions of osteocalcin were observed in the patient groups. Osteocalcin values were distributed normally in the controls as were log transformed osteocalcin values in patients and controls.

The serum concentrations (reference ranges in parentheses) of haptoglobin $(0 \cdot 2-2 \cdot 0 \mathrm{~g} / \mathrm{l})$, creatinine (64-106 $\mu \mathrm{mol} / \mathrm{l})$, albumin modified calcium $(2 \cdot 0-2 \cdot 6$ $\mathrm{mmol} / \mathrm{l})$, and alkaline phosphatase $(0 \cdot 8-4 \cdot 8 \mu \mathrm{kat} / \mathrm{l})$ were measured at the Department of Clinical Chemistry, University Hospital, Uppsala.

Wilcoxon's rank sum and signed rank tests were used for statistical analyses.

\section{Results}

Female patients with rheumatoid arthritis or other inflammatory arthritides had a geometric mean (SD range) serum osteocalcin value of $1.5(0 \cdot 6-4 \cdot 0)$ $\mu \mathrm{g} / \mathrm{l}$, which was a level significantly reduced $(\mathrm{p}<0.001)$ compared with that found in age matched healthy female controls (mean value (SD range) 3.7 $(2 \cdot 5-5 \cdot 3) \mu \mathrm{g} / \mathrm{l})$. Male patients with inflammatory arthritides had a mean osteocalcin level of $2.5 \frac{\text { ?. }}{\text {. }}$ $(1.5-3.9) \mu \mathrm{g} / \mathrm{l}$, which was significantly decreased $\vec{\Rightarrow}$ $(\mathrm{p}<0.01)$ compared with that of age matched male $\stackrel{\mathcal{O}}{7}$ controls with a mean value of $3.5(2.6-4 \cdot 7) \mu \mathrm{g} / \mathrm{l}$.

Fig. 2 shows the mean osteocalcin levels in male $\frac{\bar{\sigma}}{\bar{\omega}}$. and female patients subgrouped into rheumatoid $\vec{\nabla}$ arthritis and seronegative arthropathies. Signifi- $\varrho$ cantly reduced osteocalcin levels were found in female patients with rheumatoid arthritis $(p<0.001) \overrightarrow{0}$ and other inflammatory arthritides $(\mathrm{p}<0 \cdot 01) \mathrm{com}-\vec{\overrightarrow{ }}$ pared with those in the female controls. Significantly $\vec{\omega}$ reduced osteocalcin values were also seen in male patients with rheumatoid arthritis $(p<0.05)$ and $\stackrel{0}{\circ}$ seronegative arthropathies $(p<0.01)$ compared with of the values for male controls. Similar $(p>0.05)$ के osteocalcin levels and a similar $(p>0.05)$ degree $\stackrel{p}{\infty}$ of inflammatory activity, defined by serum hapto- + globin and erythrocyte sedimentation rate (ESR), 을 were noted in the female or male patient subgroups (Table 1).

No correlations were found between osteocalcin levels and ESR or serum haptoglobin values. This $\vec{\theta}$ was valid when calculations were performed on the whole patient population or groups of patients subdivided with respect to diagnosis, sex, and age (greater or less than 50 years old). This age was used in data handling since after the menopause higher serum osteocalcin concentrations are reported. ${ }^{13} 14 \frac{\mathrm{Q}}{\mathrm{Q}}$ There was a significant correlation between serum $\stackrel{2}{\vec{A}}$ osteocalcin and serum alkaline phosphatase only in female patients less than 50 years old $(n=10$,

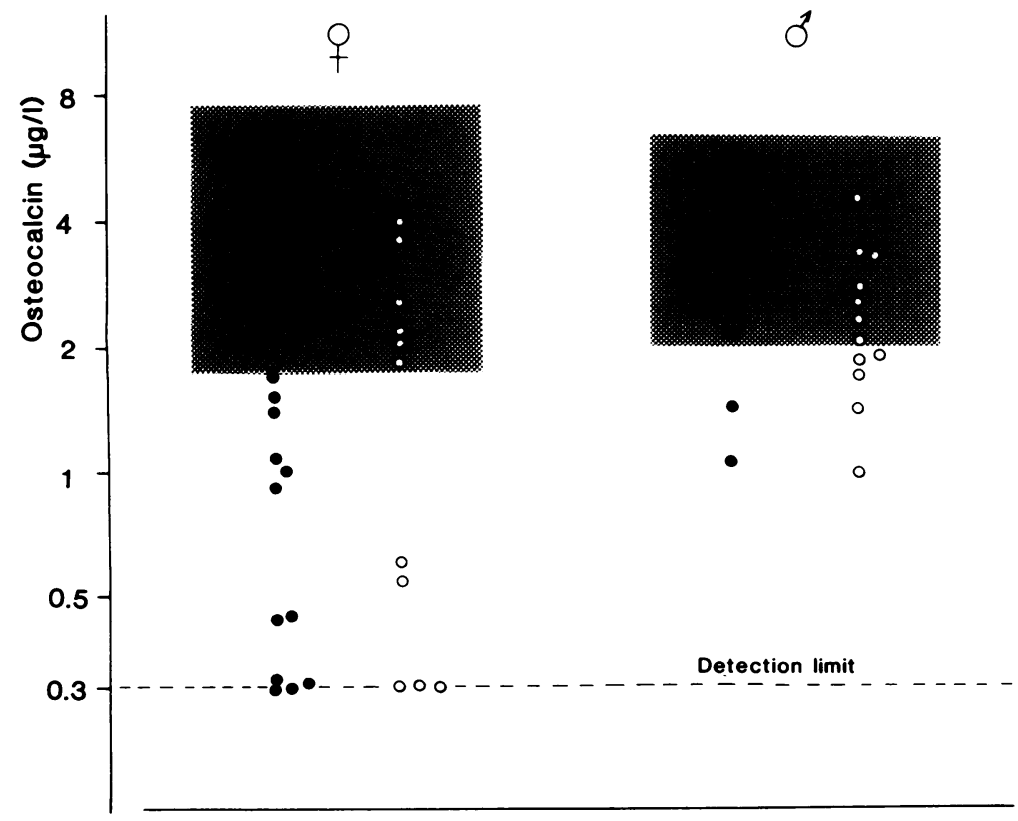

Fig. 2 Serum osteocalcin levels in $\frac{\mathrm{D}}{\mathrm{O}}$ female and male patients with rheumatoid arthritis (O) or seronegative spondyloarthropathies (○). The shaded areas represent the $2 S D$ ranges in age matched healthy men and women. 
$r=0.62, p<0.05)$. All the patients and controls had normal renal function as estimated by serum creatinine measurements. Their albumin modified serum calcium values were within the normal ranges.

The acute effects on serum osteocalcin during treatment with glucocorticoids are illustrated in Fig. 3. After one week of daily administration of 20 mg prednisolone the osteocalcin levels (mean (SEM range)) decreased from $1 \cdot 6(1 \cdot 3-2 \cdot 0)$ to $1 \cdot 0(0 \cdot 8-1 \cdot 3)$ $\mu \mathrm{g} / \mathrm{l}(\mathrm{p}<0.01)$. A similar decrease was observed in three patients given ACTH 30 IU/day (Fig. 3). In contrast, treatment with NSAIDs, indomethacin
(200 mg/day) or diclofenac (150 mg/day), did not alter the osteocalcin values; the mean levels were $1.5 \mu \mathrm{g} / \mathrm{l}(\mathrm{n}=10)$ before treatment and $1.6 \mu \mathrm{g} / \mathrm{l}$ after one week on NSAID.

During gradual reduction of the steroid dosage to $5-7.5 \mathrm{mg}$ prednisolone/day the osteocalcin levels returned to pretreatment levels. The same pattern was seen irrespective of whether the steroids were given alone or combined with azathioprine (100 $\mathrm{mg} /$ day) or cyclophosphamide (50-100 mg/day) (Fig. 4). At the start of the study the mean alkaline phosphatase level in the steroid treated group was

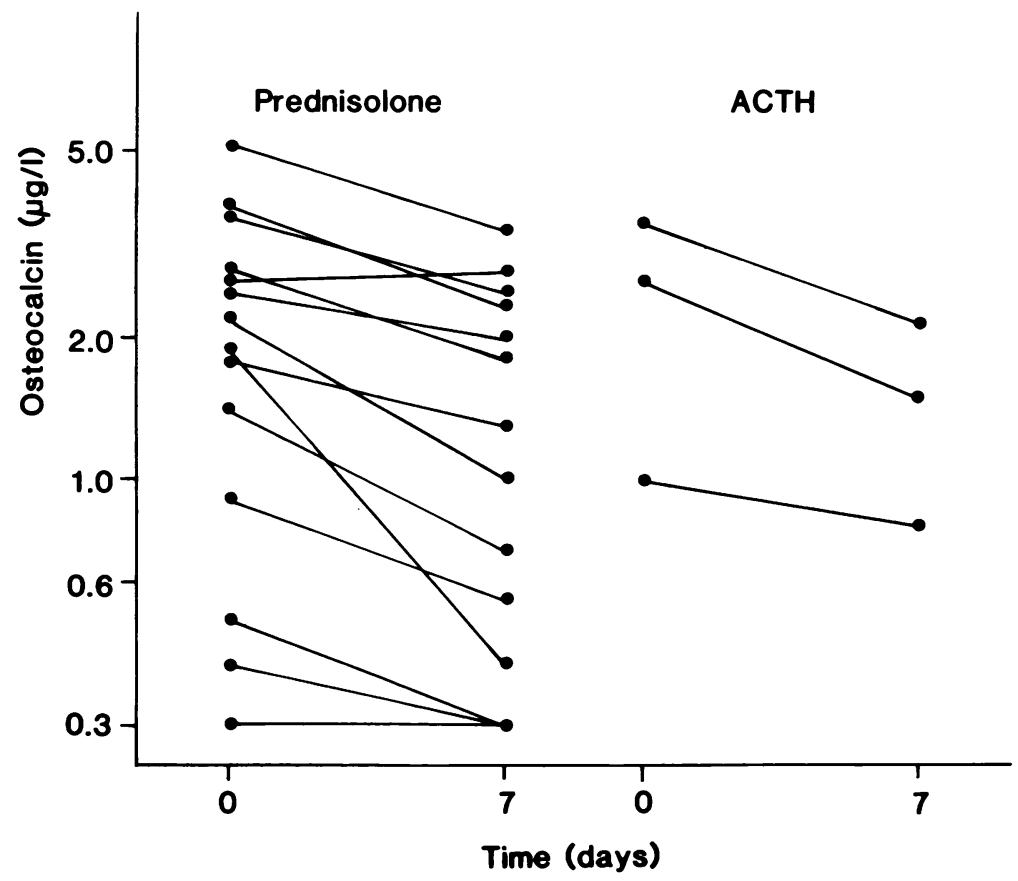

Fig. 3 The osteocalcin levels in patients with rheumatoid arthritis $(n=9)$ and seronegative spondyloarthropathies $(n=4)$ before and after one week of treatment with prednisolone $20 \mathrm{mg} /$ day ( $)$. The effect of daily injection of adrenocorticotrophic hormone (ACTH) (30 IU) for one week is also illustrated.

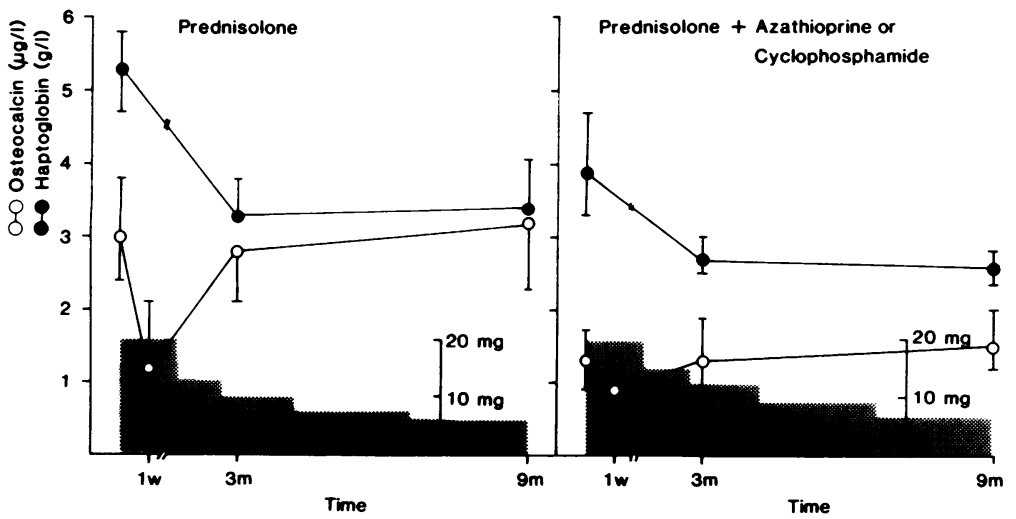

Fig. 4 Serial determinations of serum osteocalcin (mean $\pm S E M$ ) in patients with inflammatory arthritides after administration of prednisolone alone $(n=4)$ or combined with azothioprine or cyclophosphamide $(n=7)$. The mean haptoglobin levels and the average prednisolone dosages are illustrated. 


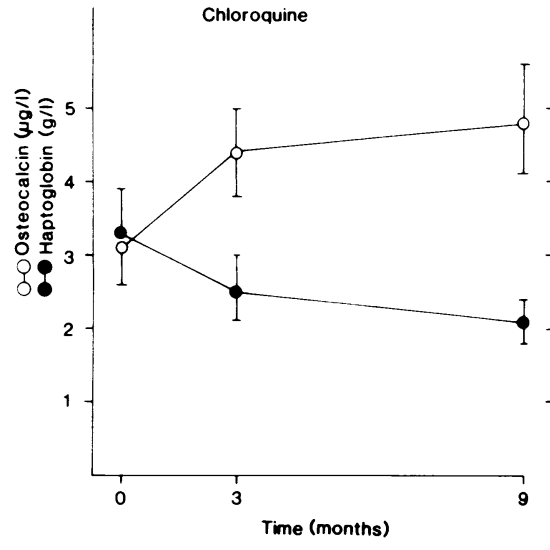

Fig. 5 Serial determinations of serum osteocalcin (mean $\pm S E M$ ) in patients with rheumatoid arthritis treated with chloroquine $(n=7)$ or penicillamine $(n=6)$. The mean haptoglobin levels and the average penicillamine dosages are illustrated. The chloroquine dosage was $250 \mathrm{mg} /$ day during the observation period.
$2 \cdot 9 \pm 0 \cdot 3(\mathrm{SEM}) \mu \mathrm{kat} / \mathrm{l}$ and remained at the same level after three months $(2 \cdot 8 \pm 0 \cdot 3)$ and nine months of treatment $(2 \cdot 9 \pm 0 \cdot 3)$.

Seven patients were studied serially during chloroquine treatment (Fig. 5). Serum osteocalcin (mean (SEM range)) at the start of the study was $3 \cdot 1$ $(2 \cdot 6-3 \cdot 7) \mu \mathrm{g} / \mathrm{l}$ and increased significantly $(\mathrm{p}<0 \cdot 01)$ after three months on therapy to $4 \cdot 4(3 \cdot 8-5 \cdot 1) \mu \mathrm{g} / \mathrm{l}$ and after another six months to $4.8(4 \cdot 1-5 \cdot 6) \mu \mathrm{g} / \mathrm{l}$ $(p<0 \cdot 01)$. An increase, which did not reach significance $(p>0.05)$, was also observed for alkaline phosphatase from $3 \cdot 0 \pm 0 \cdot 3$ (SEM) $\mu \mathrm{kat} / \mathrm{l}$ to $3 \cdot 2 \pm 0 \cdot 3$ $\mu \mathrm{kat} / \mathrm{l}$ at three months and $3.3 \pm 0.4 \mu \mathrm{kat} / \mathrm{l}$ at nine months. The same pattern was observed in patients $(n=6)$ treated with penicillamine (Fig. 5), i.e., a significant increase $(\mathrm{p}<0.05)$ of serum osteocalcin from $1.5(1 \cdot 0-2 \cdot 2) \mu \mathrm{g} / \mathrm{l}$ to $2 \cdot 2(1 \cdot 6-3 \cdot 1) \mu \mathrm{g} / \mathrm{l}$ at three months and $2 \cdot 8(2 \cdot 3-3 \cdot 4) \mu \mathrm{g} / \mathrm{l}$ at nine months after institution of the drug. At these observation times the mean alkaline phosphatase level was $2 \cdot 9 \pm 0 \cdot 4$, $3 \cdot 2 \pm 0 \cdot 5$, and $3 \cdot 4 \pm 0 \cdot 7 \mu \mathrm{kat} / \mathrm{l}$. This increase was not significant $(p>0 \cdot 05)$. The reduction of the acute phase reaction was apparent and similar in all treatment groups (Figs 4 and 5). The various drug regimens did not affect the renal function as judged by serum creatinine measurements. The individual increase of osteocalcin did not correlate with the individual reduction of haptoglobin levels obtained during treatment with chloroquine or penicillamine. Patients $(n=9)$ treated with NSAIDs and studied serially after three and nine months did not change their osteocalcin values or acute phase reactants (data not shown).

\section{Discussion}

This study shows a significant reduction in circulating osteocalcin levels in patients with rheumatoid arthritis and other inflammatory arthritides who had not received corticosteroids or remission inducing drugs.

Experimental and clinical evidence indicates that osteocalcin is produced by the osteoblasts. ${ }^{6-11}$ The kidney has a role in the metabolism of this protein, ${ }^{15}$ and an increase in circulating osteocalcin is found in uraemic patients. ${ }^{16}$ Since our patients and sex and age matched controls had no signs of abnormal renal function it is reasonable to attribute the serum reduction of osteocalcin in rheumatoid arthritis to decreased osteoblast activity. Reduced synthesis of osteocalcin does not seem to be a specific effect of any chronic illness on bone formation since normal osteocalcin serum values have been measured in various chronic diseases of non-inflammatory origin. ${ }^{17}$

Previous studies have reported other abnormalities of bone metabolism in rheumatoid arthritis. Thus the total body calcium is reduced ${ }^{18}$ and the whole body retention of ${ }^{99 \mathrm{~m}} \mathrm{Tc}$ diphosphonate is increased. ${ }^{3+}$ The uptake of ${ }^{99 \mathrm{~m}} \mathrm{Tc}$ pyrophosphate has also been reported to be increased in bones remote from the area of active synovitis, ${ }^{5}$ suggesting that patients with rheumatoid arthritis may have a generalised skeletal defect in addition to the juxtaarticular osteoporosis. The significance of increased radiopharmaceutical uptake has not been fully explained but it has been claimed to reflect an increased bone turnover in rheumatoid arthritis. ${ }^{3-5}$

The mechanisms underlying reduced circulating osteocalcin in arthritic conditions are not known and any theory regarding the possible association with altered bone metabolism must be of a highly speculative nature. We found no relation between serum osteocalcin and duration or inflammatory activity of the disease defined by ESR and acute 
phase reaction. We cannot rule out the possibility that inflammatory factors may either directly or indirectly reduce osteoblast activity since we observed during treatment with chloroquine or penicillamine an increase of circulating osteocalcin concomitant with a reduction of the inflammatory activity. Prostaglandins are considered to have an important role in the local modulation of bone cell activities. ${ }^{19}$ Although non-steroidal inhibitors of prostaglandin synthesis (NSAIDs) did not reduce the inflammatory activity or alter the osteocalcin levels in our patients, we cannot fully rule out an effect of NSAIDs on osteocalcin synthesis in inflammatory arthritides. The theoretical possibility remains that the prestudy regimen of NSAIDs in our patients that ended three to four days before the start of the study induced a continuing suppression of the osteocalcin synthesis.

Osteocalcin synthesis is influenced by states of altered parathyroid hormone (PTH) secretion and is reduced in hypoparathyroidism. ${ }^{10}$ Previous studies have reported normal basal levels of PTH in rheumatoid arthritis. ${ }^{11}$ We have recently found, however, that an acute phase reduction of serum ionised calcium by EDTA infusion induces little if any PTH increase in patients with active inflammatory connective tissue diseases in contrast with healthy individuals who increase their PTH levels about $40 \%$ (unpublished data). After successful treatment of the inflammatory condition the patients react with normal stimulation of PTH secretion after being given EDTA. Thus the possibility cannot be excluded that a defect in regulation of PTH secretion may underlie inflammatory associated reduction in osteoblast activity.

1,25 -Dihydroxyvitamin $\mathrm{D}$ is a potent stimulator of osteocalcin production both in vitro ${ }^{92}$ and in vivo. ${ }^{21}$ Previous studies have not found any abnormalities in vitamin D metabolism in rheumatoid arthritis. ${ }^{22}$ Our observation, however, that administration of prednisolone at higher dosages induced a significant reduction of serum osteocalcin after only one week of therapy is compatible with the in vitro observation that glucocorticoids inhibit the osteoblast production of osteocalcin induced by 1,25 dihydroxyvitamin D. ${ }^{20}$ This glucocorticoid effect is dose dependent in vitro, and in our patients the osteocalcin levels returned to pretreatment values during gradual reduction of the steroid dosage to $5-7.5 \mathrm{mg} /$ day. Even though the inflammatory activity became reduced at that dosage to the same extent as in patients treated with chloroquine or penicillamine, we did not observe a stimulated osteocalcin synthesis. The corticosteroid induced osteoporosis is a serious clinical side effect which is a result not only of the inhibition of osteoblast activity but also, indirectly, of a decrease in the intestinal absorption of calcium. ${ }^{23}$ At present it is premature to define the possible value of osteocalcin as a marker of the deleterious effects of corticosteroids on the skeleton.

This research was supported by grants from the Swedish Medical Research Council and Pharmacia. Sweden.

\section{References}

1 Duncan H, Frost H M. Villaneuva A R. Sigler J W. The osteoporosis of rheumatoid arthritis. Arthritis Rheum 1965; 8: 943-54.

2 Kennedy A C, Lindsay $R$. Bone involvement in rheumatoid arthritis. Clin Rheum Dis 1977: 3: 403-20.

3 Rosenspire K C, Kennedy A C, Steinbach J, Blau M, Green F A. Investigation of the metabolic activity of bone in rheumatoid arthritis. J Rheumatol 1980; 7: 469-73.

4 Steven M M. Sturrock R D, Fogelman I, Smith L. Whole body retention of diphosphonate in rheumatoid arthritis. J Rheumatol 1982; 9: 873-7.

5 Helfgott S, Rosenthall L, Esdaile J, Tannenbaum H. Generalized skeletal response to ${ }^{99 \mathrm{~m}}$ technetium methylene diphosphonate in rheumatoid arthritis. $J$ Rheumatol 1982; 9: 939-41.

6 Hauschka P V, Lian J B, Gallop P M. Direct identification of the calcium binding amino acid $\gamma$-carboxyglutamate in mineralized tissues. Proc Natl Acad Sci USA 1975; 72: 3925-9.

7 Price P A, Osuka A S. Poser J, Kristaponis J, Raman N. Characterization of $\gamma$-carboxyglutamic acid-containing protein from bone. Proc Natl Acad Sci USA 1976; 73: 1447-51.

8 Gallop P M, Lian J D, Hauschka P V. Carboxylated calcium binding protein and vitamin K. N Engl J Med 1980; 302: 1460-6.

9 Price P A, Baukol S A, 1.25-Dihydroxyvitamin D increases synthesis of the vitamin K-dependent bone protein by osteosarcoma cells. J Biol Chem 1980; 255: 11660-3.

10 Price P A, Parthemore J G, Deftos L J. New biochemical marker for bone metabolism: Measurement by radioimmunoassay of bone Gla protein in the plasma of normal subjects and patients with bone disease. J Clin Invest 1980; 66: 878-83.

11 Deftos L J, Parthemore J G, Price P A. Changes in plasma bone Gla protein during treatment of bone disease. Calcif Tissue Int 1982; 34: 121-4.

12 Epstein S, McClintock R, Bryce G, Poser J, Johnston C C, Hui $\mathrm{S}$. Differences in serum bone Gla protein with age and sex. Lancet 1984; i: $307-10$.

13 Brown J P, Delmas P D, Malaval L, Edouard C, Chapny M C, Meunier P J. Serum bone Gla-protein: a specific marker for bone formation in postmenopausal osteoporosis. Lancet 1984; i: 1091-3.

14 Ljunghall S, Hällgren R. Rastad J. Serum osteocalcin levels in normal subjects and patients with hyperparathyroidism. Exp Clin Endocrinol (in press).

15 Price P A, Williamson M K, Lothringer J W. Origin of the vitamin $\mathrm{K}$-dependent bone protein found in plasma and its clearance by kidney and bone. J Biol Chem 1981; 256: 12760-4.

16 Delmas P D, Wilson D M, Mann K G, Riggs B L. Effect of renal function on plasma levels of bone Gla-protein. $J$ Clin Endocrinol Metab 1983; 57: 1028-30.

17 Slovik D M. Gundberg C M. Neer R M. Lian J B. Clinical evaluation of bone turnover by serum osteocalcin measurements in a hospital setting. $J$ Clin Endocrinol Metab 1984; 59: 228-30.

18 Reid D M, Kennedy N S J, Smith M A, Tothill P, Nuki G. Total body calcium in rheumatoid arthritis: effects of disease activity and corticosteroid treatment. Br Med J 1982; 285: 330-2. 
19 Tashjian A H, Tice J C, Sides K. Biological activities of prostaglandin analogues and metabolites on bone in organ culture. Nature 1977; 266: 645-7.

20 Beresford J N, Gallagher J A. Poser J W, Russell R G G. Production of osteocalcin by human bone cells in vitro. Effects of $1.25(\mathrm{OH})_{2} \mathrm{D}_{3}, 24.25(\mathrm{OH})_{2} \mathrm{D}_{3}$. parathyroid hormone. and glucocorticoids. Metab Bone Dis Relat Res 1984: 5: 229-34.

21 Gundberg C M, Cole D E. Lian J B. Reade T M. Gallop P M. Serum osteocalcin in the treatment of inherited rickets with 1,25-dihydroxyvitamin $\mathrm{D}_{3}$. J Clin Endocrinol Metab 1983; 56: 1063-7.

22 Bird H A. Wright V. Hennes U. Theiss E. Comparison of serum 1.25-dihydroxycholecalciferol concentrations in rheumatoid arthritis and osteoarthrosis. Ann Rheum Dis 1982; 41: 257-8.

23 Caniggia A, Nuti R. Lore F, Vattimo A. Pathophysiology of the adverse effects of glucoactive corticosteroids on calcium metabolism in man. J Steroid Biochem 1981; 15: 153-61. 